(C) 2021, The Authors. Published by Elsevier Inc. and Fass Inc. on behalf of the American Dairy Science Association ${ }^{\circledR}$. This is an open access article under the CC BY-NC-ND license (http://creativecommons.org/licenses/by-nc-nd/4.0/).

\title{
Lactose oxidase: An enzymatic approach to inhibit Listeria monocytogenes in milk
}

\author{
Brenna T. Flynn, $\odot$ Sarah M. Kozak, $\odot$ Marie R. Lawton, $\odot$ and Samuel D. Alcaine* ${ }^{*}$ \\ Department of Food Science, Cornell University, Ithaca, NY 14853
}

\begin{abstract}
Listeria monocytogenes is a ubiquitous pathogen that can cause morbidity and mortality in immunocompromised individuals. Growth of L. monocytogenes is possible at refrigeration temperatures due to its psychrotrophic nature. The use of antimicrobials in dairy products is a potential way to control L. monocytogenes growth in processes with no thermal kill step, thereby enhancing the safety of such products. Microbial-based enzymes offer a clean-label approach for control of $L$. monocytogenes outgrowth. Lactose oxidase (LO) is a microbial-derived enzyme with antimicrobial properties. It oxidizes lactose into lactobionic acid and reduces oxygen, generating $\mathrm{H}_{2} \mathrm{O}_{2}$. This study investigated the effects of LO in UHT skim milk using different L. monocytogenes contamination scenarios. These LO treatments were then applied to raw milk with various modifications; higher levels of LO as well as supplementation with thiocyanate were added to activate the lactoperoxidase system, a natural antimicrobial system present in milk. In UHT skim milk, concentrations of 0.0060, 0.012, and $0.12 \mathrm{~g} / \mathrm{L} \mathrm{LO}$ each reduced L. monocytogenes counts to below the limit of detection between 14 and $21 \mathrm{~d}$ of refrigerated storage, dependent on the concentration of LO. In the 48-h trials in UHT skim milk, LO treatments were effective in a concentrationdependent fashion. The highest concentration of LO in the 21-d trials, $0.12 \mathrm{~g} / \mathrm{L}$, did not show great inhibition over $48 \mathrm{~h}$, so concentrations were increased for these experiments. In the lower inoculum, after $48 \mathrm{~h}$, a 12 $\mathrm{g} / \mathrm{L}$ LO treatment reached levels of $1.7 \mathrm{log} \mathrm{cfu} / \mathrm{mL}$, a reduction of $1.3 \mathrm{log} \mathrm{cfu} / \mathrm{mL}$ from the initial inoculum, whereas the control grew out to approximately $4 \log \mathrm{cfu} / \mathrm{mL}$, an increase of $1 \log \mathrm{cfu} / \mathrm{mL}$ from the inoculum on $\mathrm{d} 0$. When a higher challenge inoculum of $5 \log \mathrm{cfu} / \mathrm{mL}$ was used, the $0.12 \mathrm{~g} / \mathrm{L}$ and $1.2 \mathrm{~g} / \mathrm{L}$ treatments reduced the levels by 0.2 to $0.3 \log \mathrm{cfu} / \mathrm{mL}$
\end{abstract}

Received March 13, 2021.

Accepted June 16, 2021.

*Corresponding author: alcaine@cornell.edu below the initial inoculum and the $12 \mathrm{~g} / \mathrm{L}$ treatment by $>1 \log \mathrm{cfu} / \mathrm{mL}$ below the initial inoculum by hour 48 of storage at refrigeration temperatures. After the efficacy of LO was determined in UHT skim milk, LO treatments were applied to raw milk. Concentrations of LO were increased, and the addition of thiocyanate was investigated to supplement the effect of the lactoperoxidase system against L. monocytogenes. When raw milk was inoculated with $2 \log \mathrm{cfu} / \mathrm{mL}, 1.2 \mathrm{~g} / \mathrm{L}$ LO alone and combined with sodium thiocyanate reduced $\sim 0.8 \log \mathrm{cfu} / \mathrm{mL}$ from the initial inoculum on $\mathrm{d} 7$ of storage, whereas the control grew out to $>1 \log \mathrm{cfu} /$ $\mathrm{mL}$ from the initial inoculum. Furthermore, in the higher inoculum, $1.2 \mathrm{~g} / \mathrm{L}$ LO combined with sodium thiocyanate reduced L. monocytogenes counts from the initial inoculum by $>1 \log \mathrm{cfu} / \mathrm{mL}$, whereas the control grew out $2 \log \mathrm{cfu} / \mathrm{mL}$ from the initial inoculum. Results from this study suggest that LO is inhibitory against L. monocytogenes in UHT skim milk and in raw milk. Therefore, LO may be an effective treatment to prevent L. monocytogenes outgrowth, increase the safety of raw milk, and be used as an effective agent to prevent L. monocytogenes proliferation in fresh cheese and other dairy products. This enzymatic approach is a novel application to control the foodborne pathogen $L$. monocytogenes in dairy products.

Key words: Listeria, lactose oxidase, milk, enzyme, lactoperoxidase

\section{INTRODUCTION}

Listeria monocytogenes is a ubiquitous, gram-positive, facultative anaerobe that grows at refrigeration temperatures (Berger, 2017; FDA, 2019b). The pathogen is found throughout the environment, specifically in soil and water. Listeria monocytogenes may survive in food that has a relatively high acid and salt content and can tolerate high and low temperatures (FDA, 2018). Due to its ubiquitous nature and the readyto-eat nature of dairy products, L. monocytogenes is a pathogen of concern for dairy processors (Boor et al., 2017). It can contaminate bulk tank milk samples from nonhygienic sampling of the cow udder or from 
the cow-milking equipment (Fedio and Jackson, 1992). Listeria monocytogenes may contaminate raw milk products as observed from past outbreaks, but it can also contaminate products postpasteurization from the dairy environment where it can survive for years, making it a danger in both raw and pasteurized dairy products (Boor et al., 2017).

Ingestion of L. monocytogenes has the potential to cause the disease listeriosis among children, immunocompromised individuals, pregnant women, and the elderly. Epidemiological studies in the United States have shown that L. monocytogenes has some of the highest hospitalization and case-fatality rates of all the foodborne pathogens (Mead et al., 1999), making it a danger to society if improper protocols are followed in food processing facilities. It was estimated by de Noordhout et al. (2014) that globally the burden of listeriosis was 23,150 illnesses and 5,463 deaths in 2010 . In the United States, dairy products, such as fresh soft cheeses, hard cheeses, and soft-ripened cheeses were most commonly associated with $L$. monocytogenes contamination in the cheese category between 1986 and 2008 and have resulted in numerous deaths (FDA, 2015). Furthermore, there have been 7 outbreaks in the United States associated with L. monocytogenes since 2011 that caused illness and death from dairy product consumption (Centers for Disease Control and Prevention, 2020). Globally, contamination of soft and soft-ripened cheeses with $L$. monocytogenes continues to occur, as these cheese types have low salt content, near-neutral $\mathrm{pH}$, and high water activity (Barría et al., 2020). Therefore, if contaminated postpasteurization, L. monocytogenes can grow to dangerous levels (Van Tassell et al., 2015; Lawton et al., 2020).

In addition to fresh cheeses, L. monocytogenes may pose a threat to cheeses made with raw milk. In the United States, unpasteurized milk cheeses must be aged at a temperature of at least $1.7^{\circ} \mathrm{C}$ and held for $60 \mathrm{~d}$ before distribution (21 CFR 133.182(a); FDA, 2020a). In a raw milk, soft-ripened cheese risk assessment, the US Food and Drug Administration (FDA) predicted that $4.7 \%$ of cheeses had L. monocytogenes contamination. According to this risk assessment, reducing contamination in the manufacture of raw milk cheese by a factor of $3 \log _{10}, 4 \log _{10}$, or $5 \log _{10}$ would reduce the average risk of an immunocompromised individual or pregnant woman from becoming sick from cheese contaminated with L. monocytogenes. The addition of an antimicrobial on the cheese surface that could reduce $L$. monocytogenes contamination by $2 \log _{10}$ cfu would provide a lower risk to immunocompromised individuals than consuming cheese with no antimicrobial treatment (FDA, 2015).
The ubiquitous nature of $L$. monocytogenes and its potential to contaminate dairy products has led to the evaluation of different methods to inhibit the pathogen in milk and cheese products (Boor et al., 2017). High pressure processing as a control strategy has the advantage of inactivating $L$. monocytogenes with minimal disruption of cheese quality (Tomasula et al., 2014). Addition of antimicrobials including bacteriocins and other generally recognized as safe (GRAS) substances such as organic acids have been evaluated to be applied alone or in combination to reduce the amount needed for protection (Van Tassell et al., 2015; Kozak et al., 2018). Protective cultures, commonly lactic acid bacteria, can inhibit pathogen growth through production of acids or bacteriocins or competition for nutrients. This strategy is dependent on the specific cheese matrix and how cultures thrive in its environment due to factors such as water activity and pH (Coelho et al., 2014; Lawton et al., 2020). Listeria monocytogenes outgrowth over time has been shown in different experiments that tested different methodology at inhibiting the pathogen (Van Tassell et al., 2015; Kozak et al., 2018). D'Amico et al. (2008) found that L. monocytogenes still had the potential to grow even after the 60-d storage period required by the $21 \mathrm{CFR}$ in both raw and pasteurized milk cheeses, meaning an effective method to combat this outgrowth is necessary.

Listeria monocytogenes outgrowth and consumption in raw milk or contaminated cheeses can pose a serious health risk, especially as consumers move toward a trend of eating unprocessed or minimally processed food (Ricchi et al., 2019). Some consumers view common production methods and ingredients as "unnatural" or "artificial," causing difficulties in the addition of antimicrobial treatments. There is currently no definition of a clean label by a regulatory authority. Consumers often view foods produced with an artificial ingredient as not falling under the clean-label category (Asioli et al., 2017).

With consumers moving toward a trend of desiring "clean labels," clean-label antimicrobial treatments that are effective against L. monocytogenes are needed in dairy products. Lactose oxidase $(\mathbf{L O})$ is an enzyme that many consumers would categorize in the cleanlabel category because it is commercially produced by a strain of mold, Microdochium nivale. Enzymes made from plant or microbial products are often used as effective coagulants for cheese, so consumers may be primed to view LO as naturally occurring in dairy products (Ben Amira et al., 2017).

Lactose oxidase oxidizes lactose into lactobionic acid (LBA; Ahmad et al., 2004) as it concurrently reduces $\mathrm{O}_{2}$ into $\mathrm{H}_{2} \mathrm{O}_{2}$ (Nordkvist et al., 2007). $\mathrm{H}_{2} \mathrm{O}_{2}$ is GRAS 
Flynn et al.: INHIBITION OF LISTERIA MONOCYTOGENES IN MILK

Table 1. Strains of Listeria monocytogenes used to produce a cocktail used for inoculation of milk samples

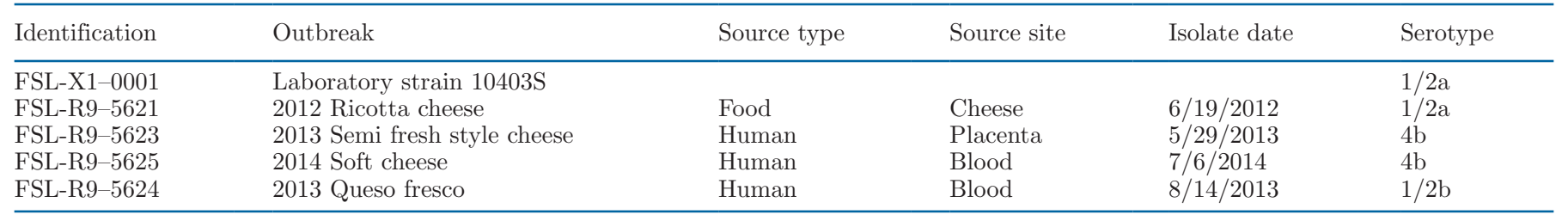

and can be used as an antimicrobial agent in different production processes within the United States (FDA, 2019a). In the European Union, $\mathrm{H}_{2} \mathrm{O}_{2}$ is only allowed as a processing aid for certain foodstuffs, such as the whitening of fish (Himonides et al., 1999); however, the use of glucose oxidase, an enzyme which also produces hydrogen peroxide (Duke et al., 1969) is allowed as an additive in certain foods (EFSA CEP Panel et al., 2019). $\mathrm{H}_{2} \mathrm{O}_{2}$ has been shown as an effective agent in inhibiting $L$. monocytogenes in milk, and its combination with thiocyanate (TCN) has been deemed to be an effective activator of the lactoperoxidase system (LPDS), a natural antimicrobial system in milk (Kussendrager and van Hooijdonk, 2000; FAO, 2006). The LO inhibited L. monocytogenes both alone and in combination with TCN using an inhibition assay in a previous study (Lara-Aguilar and Alcaine, 2019b). Its usefulness in fluid milk and cheese products as an inhibitor of $L$. monocytogenes has not yet been explored.

The purpose of this study was to evaluate LO as an antimicrobial in fluid milk inoculated with $L$. monocytogenes. The first part of this study explored the efficacy of $\mathrm{LO}$ on the growth of $L$. monocytogenes in UHT skim milk inoculated at $2 \mathrm{log} \mathrm{cfu} / \mathrm{mL}$ and $4 \mathrm{log}$ $\mathrm{cfu} / \mathrm{mL}$ over a 21 -d storage period. These results were then used to determine if increasing concentrations of LO showed improved efficacy against $L$. monocytogenes inoculated at $3 \log \mathrm{cfu} / \mathrm{mL}$ and $5 \log \mathrm{cfu} / \mathrm{mL}$ in UHT skim milk over $48 \mathrm{~h}$. Last, it was investigated whether LO inhibited L. monocytogenes growth in raw milk when stored at refrigeration temperatures. Our results showed that LO has potential as a prevention strategy for L. monocytogenes outgrowth in fluid dairy products.

\section{MATERIALS AND METHODS}

\section{Listeria monocytogenes Cocktail Preparation}

Five isolates of Listeria monocytogenes (Table 1), 4 isolated from fresh cheese outbreaks and 1 local laboratory strain, were obtained from the Food Safety Laboratory at Cornell University (Ithaca, NY). Each isolate was streaked onto Brain Heart Infusion (BHI) agar and incubated at $37^{\circ} \mathrm{C}$ for $24 \mathrm{~h}$. After incubation, a sterile inoculation loop was used to transfer an individual colony of each strain into $5 \mathrm{~mL}$ of BHI broth. Broth cultures were grown at $37^{\circ} \mathrm{C}$ for $18 \mathrm{~h}$ to obtain cultures of optical density $=1.00(9 \log \mathrm{cfu} / \mathrm{mL})$. A Listeria cocktail was prepared by transferring 1,000 $\mu \mathrm{L}$ of each broth into a sterile tube and vortexed to combine. The cocktail was serially diluted in PBS and plated onto BHI agar to confirm target inoculum levels.

\section{Application of LO in UHT Skim Milk}

We used UHT-processed skim milk (Parmalat USA Corp.) to minimize background microflora. Twenty-five milliliters of milk was aseptically transferred to individual 50-mL tubes (VWR International) and treated with various levels of $\mathrm{LO}$ to produce final concentrations of 0.006, 0.012, and $0.12 \mathrm{~g} / \mathrm{L}$ (LactoYield, Chr. Hansen). One hundred microliters of the L. monocytogenes cocktail described above were added into each treatment to obtain an approximate microbial load of $2 \log \mathrm{cfu} / \mathrm{mL}$ or $4 \log \mathrm{cfu} / \mathrm{mL}$. Inoculated milk with no LO was used as a positive control. Milk with no LO that was not inoculated with $L$. monocytogenes was used as a negative control to confirm absence of $L$. monocytogenes in the commercial product. Samples were stored at $6^{\circ} \mathrm{C}$ for $21 \mathrm{~d}$ with samples for microbiological load taken on d $0,2,4,7,14$, and 21 . At each time point, each treatment was sampled from the same tube in duplicate for all experiments. Before plating, serial dilutions of each sample were prepared in PBS. Listeria counts were enumerated at all sampling points by spread plating in duplicate on Modified Oxford Agar (MOX), and plates were incubated at $30^{\circ} \mathrm{C}$ (Curtis et al., 1989; Henderson et al., 2019) for $48 \mathrm{~h}$. The $\mathrm{pH}$ of each sample was taken in duplicate at all sampling points using established methodology (Wehr and Frank, 2004). For all pH measurements, an InLab Smart Pro-ISM pH probe (Mettler Toledo) connected to an iCinac (AMS Alliance) was used. The experiment was performed in triplicate.

\section{High Concentration of LO in UHT Skim Milk Over 48 h}

Twenty-five milliliters of UHT skim milk (Parmalat USA Corp.) was aseptically transferred to individual tubes and treated with various levels of LO to produce 
final concentrations of $0.12,1.2$, and $12 \mathrm{~g} / \mathrm{L}$ (LactoYield, Chr. Hansen). One hundred microliters of the Listeria cocktail were inoculated into each treatment to obtain an approximate microbial load of $3 \log \mathrm{cfu} /$ $\mathrm{mL}$ or $5 \log \mathrm{cfu} / \mathrm{mL}$. Inoculated milk with no LO was used as the positive control. Milk with no LO that was not inoculated with L. monocytogenes was used as the negative control to confirm the absence of the pathogen in the commercial product. Samples were stored at $6^{\circ} \mathrm{C}$ for $48 \mathrm{~h}$ of storage with samples for microbiological load taken at h $0,2,4,6,8,12,24,36$, and 48 . Before plating, serial dilutions of each sample were prepared in PBS. Listeria counts were enumerated at all sampling points by spread plating in duplicate on MOX, and plates were incubated at $30^{\circ} \mathrm{C}$ for $48 \mathrm{~h}$. The $\mathrm{pH}$ of each sample was taken in duplicate at all sampling points. The experiment was repeated in triplicate.

\section{Application of LO and TCN in Raw Milk}

Raw whole milk was collected from the Cornell University Dairy Plant $3 \mathrm{~h}$ after milking and stored at refrigeration temperatures for $1 \mathrm{~d}(24 \mathrm{~h})$ before performing the experiment. Raw milk was shaken before sampling to ensure homogeneity. Twenty-five milliliters of milk was aseptically transferred to tubes and treated with various levels of LO and TCN (VWR International). We added LO to milk to produce final concentrations of $0.12,0.6$, and $1.2 \mathrm{~g} / \mathrm{L}$. Following the addition of LO, TCN was added to obtain a final concentration of 14 $\mathrm{mg} / \mathrm{L}$. One hundred microliters of the Listeria cocktail was inoculated into each treatment to obtain an approximate microbial load of $2 \log \mathrm{cfu} / \mathrm{mL}$ or $4 \log \mathrm{cfu} /$ $\mathrm{mL}$. One treatment of each $\mathrm{LO}$ concentration did not include the addition of TCN, and inoculated milk with no LO was used as the positive control. Milk without LO that was not inoculated with $L$. monocytogenes was used as the negative control to confirm the absence of the pathogen in the raw milk produced from Cornell. Samples were stored at $6^{\circ} \mathrm{C}$ for $7 \mathrm{~d}$ of storage with samples for microbiological load taken on d 0,2 , 4, and 7. Before plating, serial dilutions of each sample were prepared in PBS. Listeria counts were enumerated by spread plating in duplicate on MOX, and plates were incubated at $30^{\circ} \mathrm{C}$ for $48 \mathrm{~h}$. The total aerobic count of the negative control was determined by plating the serial dilutions on Standard Plate Count (SPC) agar and incubating plates at $32^{\circ} \mathrm{C}$ for $48 \mathrm{~h}$. The $\mathrm{SPC}$ counts were not taken in the UHT trials because the high heat and time of UHT pasteurization produces a microbially shelf-stable product. The $\mathrm{pH}$ of each sample was taken in duplicate at all sampling points. The experiment was repeated in triplicate.

\section{Statistical Analysis}

All statistical analyses were performed using $\mathrm{R}$ software (version 3.5.2, https://www.r-project.org/). We performed ANOVA and Tukey's honest significant difference tests at each time point to determine log differences in Listeria counts between all treatments and the positive control. The same tests were performed at each time point to determine differences in $\mathrm{pH}$ values between all treatments and the negative control.

\section{RESULTS AND DISCUSSION}

\section{Application of LO in UHT Skim Milk Results in a Bacteriostatic Effect Against L. monocytogenes}

In previous work, it was shown that background microbiota could have an effect on LO efficacy (LaraAguilar and Alcaine, 2019a) on the target bacteria. To understand the interaction between LO and L. monocytogenes, we initially used UHT skim milk to have a dairy environment that was free from background microbiota. Multiple concentrations of LO were added to UHT milk, and their efficacy to control L. monocytogenes outgrowth was monitored. Four of the isolates used for the L. monocytogenes challenge cocktail were from fresh cheese outbreaks, and one was a reference laboratory strain. The treatments were challenged with both a high, $4 \log \mathrm{cfu} / \mathrm{mL}$, and a low, $2 \log \mathrm{cfu} / \mathrm{mL}$, inoculum to represent variable contamination scenarios.

When L. monocytogenes was inoculated at a target inoculum of $2 \log \mathrm{cfu} / \mathrm{mL}$, all $\mathrm{LO}$ treatments resulted in a reduction in the number of $L$. monocytogenes when compared with the control starting at d 2 of storage (Figure 1). Within $2 \mathrm{~d}$ of storage, a $0.78 \mathrm{log} \mathrm{cfu} / \mathrm{mL}$ outgrowth of the control was observed, whereas each treatment group inhibited outgrowth of L. monocytogenes. This trend continued throughout the rest of the 21-d trial (Table 2). Significant differences $(P<0.05)$ between each treatment and the control were shown starting on d 2 of storage and continued throughout the trial. By d 21, the control outgrowth reached 8 log cfu/ $\mathrm{mL}$, whereas each treatment group fell below the limit of detection (LOD).

When L. monocytogenes was inoculated at a higher level of $4 \log \mathrm{cfu} / \mathrm{mL}$ (Figure 2), the control differed significantly $(P<0.05)$ from groups treated with LO within $48 \mathrm{~h}$ of storage. By d 4 of storage, the L. monocytogenes outgrowth was observed in the control, whereas each treatment group remained below the initial inoculation level. By d 7, outgrowth in the control reached $7.2 \log \mathrm{cfu} / \mathrm{mL}$, whereas each treatment group fell below that in a concentration-dependent fashion (0.006 


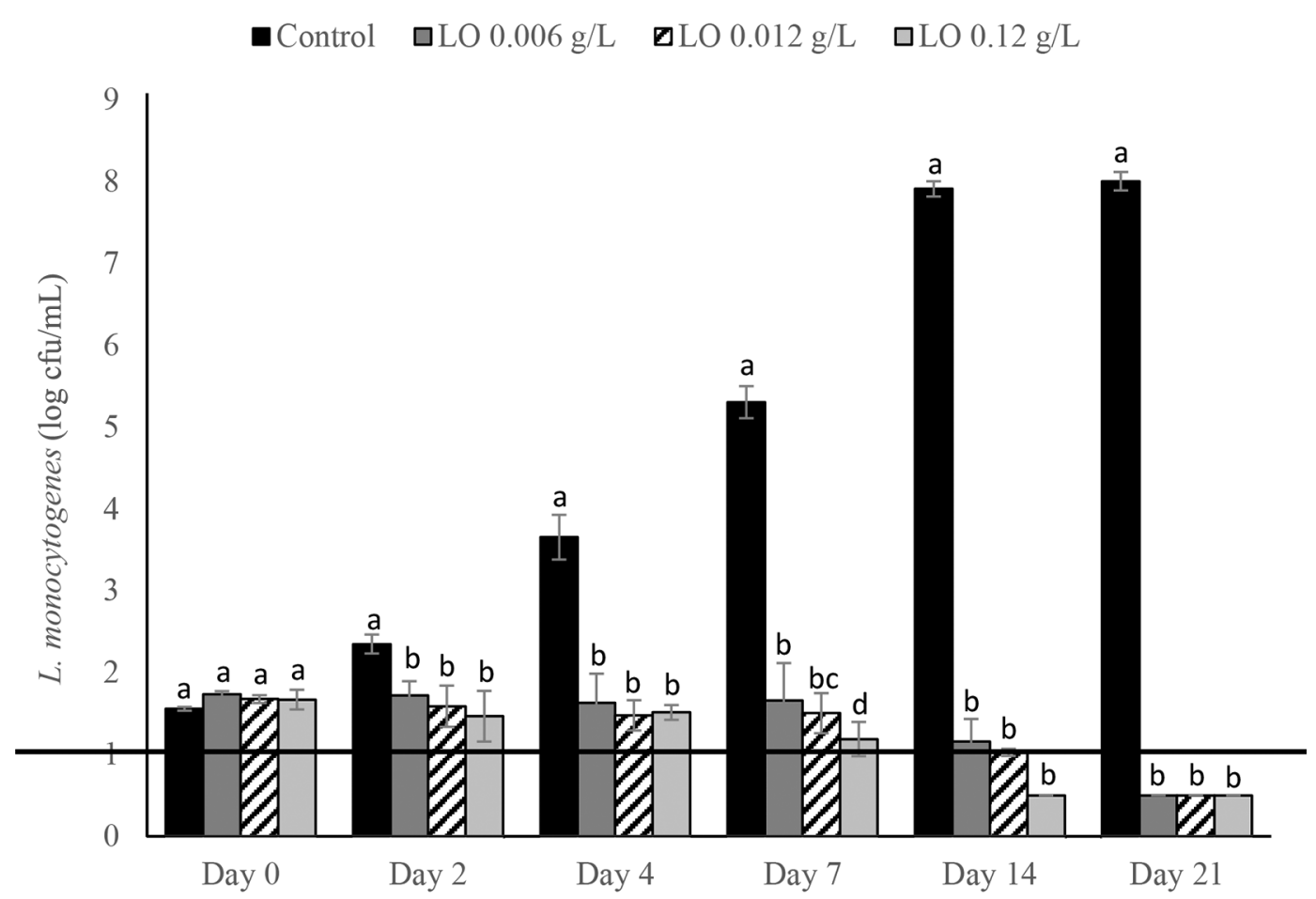

Figure 1. Listeria monocytogenes counts inoculated at $2 \mathrm{log} \mathrm{cfu} / \mathrm{mL}$ in UHT skim milk treated with lactose oxidase (LO) during storage at $6^{\circ} \mathrm{C}$. Numbers on the treatment label indicate the concentration of LO solution $(\mathrm{g} / \mathrm{L}$ ). Bars with different letters (a-d) indicate significant differences $(P<0.05)$ between treatments on the same day. For counts lower than the limit of detection, a value of $0.5 \log 10 \mathrm{cfu} / \mathrm{mL}$ was used. A horizontal line was drawn at the limit of detection to represent $\mathrm{y}=1.0 \mathrm{log} \mathrm{cfu} / \mathrm{mL}$. The 0.006 and $0.012 \mathrm{~g} / \mathrm{L}$ treatments were undetectable in $21 \mathrm{~d}$, and the $0.12 \mathrm{~g} / \mathrm{L}$ treatment was undetectable in $14 \mathrm{~d}$. Error bars represent the SD.

$\mathrm{g} / \mathrm{L}=3.6,0.012 \mathrm{~g} / \mathrm{L}=3.4,0.12=2.8 \log \mathrm{cfu} / \mathrm{mL}) . \mathrm{On}$ d 14, the control reached levels of above $8 \log \mathrm{cfu} / \mathrm{mL}$, and reduction of L. monocytogenes was shown for each treatment group. Even at the lowest concentration of LO $(0.006 \mathrm{~g} / \mathrm{L})$, the treatment fell to $2.0 \log \mathrm{cfu} / \mathrm{mL}$ compared with the initial inoculation of approximately $4 \log \mathrm{cfu} / \mathrm{mL}$. At a concentration of $0.012 \mathrm{~g} / \mathrm{L}$, the count of L. monocytogenes dropped to $1.6 \log \mathrm{cfu} / \mathrm{mL}$. At the highest concentration of LO, the number of $L$. monocytogenes was reduced below the LOD. By d 21 of storage, all treatment groups fell below the LOD.

These results suggested the production of $\mathrm{H}_{2} \mathrm{O}_{2}$ from the presence of LO in milk was sufficient to cause $L$. monocytogenes to fall below the LOD with no regrowth after long-term storage. A previous study (Lara-Aguilar and Alcaine, 2019b) screened LO against a set of dairyrelevant microorganisms, including $L$. monocytogenes using a well-diffusion assay. A zone of clearing was observed around the LO wells. However, when catalase was spotted next to the well, $L$. monocytogenes growth was observed, suggesting that the production of $\mathrm{H}_{2} \mathrm{O}_{2}$ was the driving cause of bacterial inhibition of LO.

In both our contamination scenarios, L. monocytogenes outgrowth was inhibited by LO in comparison to the control starting at $\mathrm{d} 2$ of storage and lasted throughout the rest of the trial. According to the FDA

Table 2. $\mathrm{pH}( \pm \mathrm{SD})$ of UHT skim milk treated with lactose oxidase $(\mathrm{LO})$ stored at $6^{\circ} \mathrm{C}$

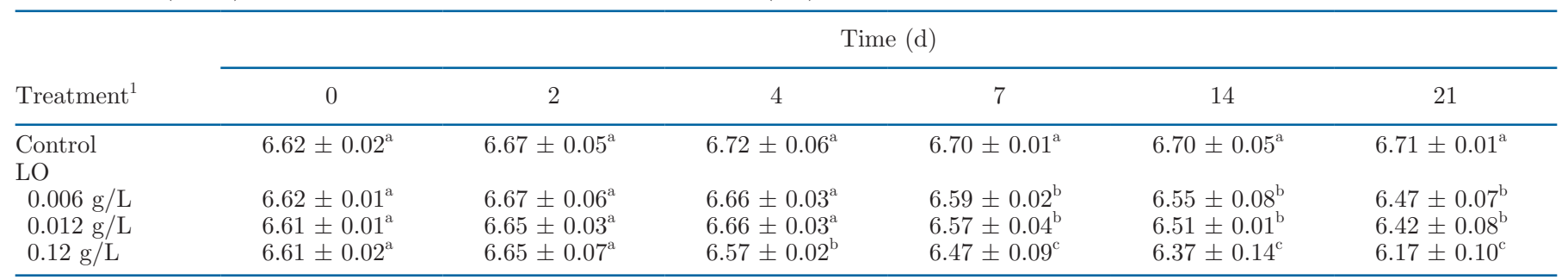

\footnotetext{
${ }^{\mathrm{a}-\mathrm{c}}$ Means within a column with different superscript letters are significantly different $(P<0.05)$ between treatments.
} 


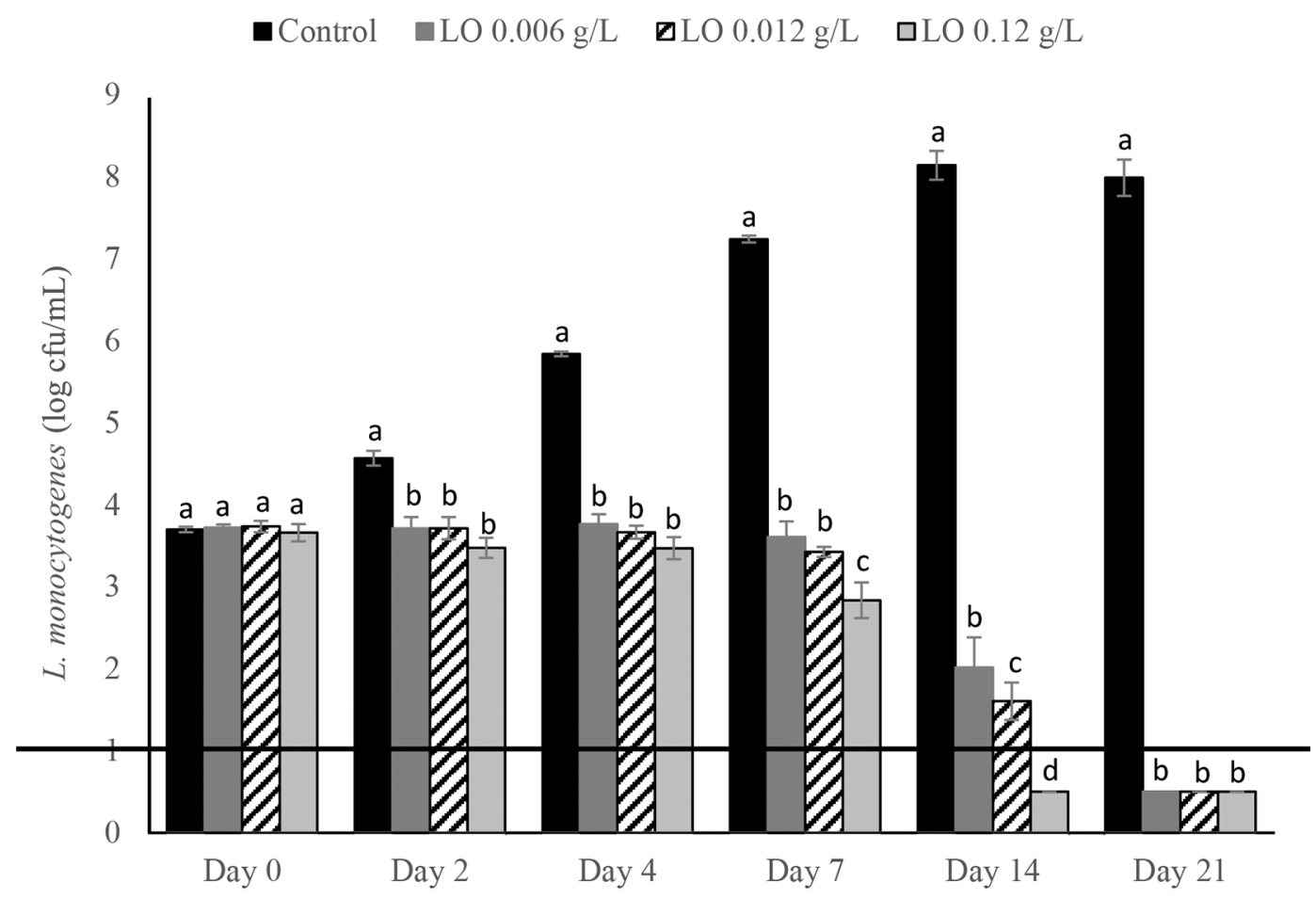

Figure 2. Listeria monocytogenes counts inoculated at $4 \mathrm{log} \mathrm{cfu} / \mathrm{mL}$ in UHT skim milk treated with lactose oxidase (LO) during storage at $6^{\circ} \mathrm{C}$. Numbers on the treatment label indicate the concentration of LO solution $(\mathrm{g} / \mathrm{L})$. Bars with different letters (a-d) indicate significant differences $(P<0.05)$ between treatments on the same day. For counts lower than the limit of detection, a value of $0.5 \mathrm{log} 10 \mathrm{cfu} / \mathrm{mL} \mathrm{was}$ used. A horizontal line was drawn at the limit of detection to represent $\mathrm{y}=1.0 \mathrm{log} \mathrm{cfu} / \mathrm{mL}$. The 0.006 and $0.012 \mathrm{~g} / \mathrm{L}$ treatments were undetectable in $21 \mathrm{~d}$, and the $0.12 \mathrm{~g} / \mathrm{L}$ treatment was undetectable in $14 \mathrm{~d}$. Error bars represent the SD.

risk assessment, a listeriostatic process control measure shows an average increase of less than $1 \log$ cycle over 2 or more time intervals in the number of L. monocytogenes in replicate trials with the food of interest. A listericidal process control is one that provides a reduction of 5 orders of magnitude (FDA, 2015). According to these results, even at the lowest concentration of LO, listeriostatic inhibition was observed.

The relative safety of $\mathrm{H}_{2} \mathrm{O}_{2}$ means it has many uses in the food industry (Linley et al., 2012), such as a sanitizer on food contact surfaces to provide an antimicrobial effect (Govaert et al., 2019), and as a food additive to reduce microbial contamination. According to the 21 Code of Federal Regulations, $\mathrm{H}_{2} \mathrm{O}_{2}$ may be added to milk and other food products at a maximum concentration of $0.05 \%$ to milk intended for cheesemaking [21 CFR 184(a); FDA, 2020b]. Main advantages of using $\mathrm{H}_{2} \mathrm{O}_{2}$ in the food industry are that it has broadspectrum activity and lack of environmental toxicity following its complete degradation (Linley et al., 2012). $\mathrm{H}_{2} \mathrm{O}_{2}$ has a long history of use worldwide for milk preservation (Martin et al., 2014). It has also been shown to be an effective antimicrobial in different food products. It was used as an effective antimicrobial to reduce counts of L. monocytogenes on mung bean sprouts after combination with a hot water treatment. These counts were reduced by approximately $2 \mathrm{log} \mathrm{cfu} / \mathrm{g}$ on mung beans after storage (Trzaskowska et al., 2018). Kozak et al. (2018) found that a concentration of $\mathrm{H}_{2} \mathrm{O}_{2}$ of $100 \mathrm{mg} / \mathrm{L}$ inhibited growth of $L$. monocytogenes when stored at $7^{\circ} \mathrm{C}$ in whole milk. Overall, there was a $2.5 \mathrm{log}$ $\mathrm{cfu} / \mathrm{mL}$ reduction in the number of $L$. monocytogenes when $\mathrm{H}_{2} \mathrm{O}_{2}$ was added at this concentration. Concentrations of $400 \mathrm{mg} / \mathrm{L}$ were bactericidal within $24 \mathrm{~h}$ of storage. Our results are consistent with the reduction of $L$. monocytogenes found in previous studies due to $\mathrm{H}_{2} \mathrm{O}_{2}$ production.

There is little literature regarding the exact mechanism behind bacterial death via $\mathrm{H}_{2} \mathrm{O}_{2}$. It is an oxidative biocide, meaning it removes electrons from susceptible chemical groups, oxidizing them and then becoming reduced. Oxidative biocides may severely damage microbial structures, causing the release of intracellular compounds, which are then oxidized (Finnegan et al., 2010). $\mathrm{H}_{2} \mathrm{O}_{2}$ may then act via the formation of hydroxy radicals that oxidize thiol groups in enzymes and proteins (Russell, 2003). It is currently believed that the Fenton reaction leading to the production of free hy- 
droxy radicals is the basis of the reaction, and evidence exists for the reaction of this leading to the oxidation of DNA, proteins, and lipids in vivo (Linley et al., 2012).

Lactase oxidase also produces LBA at the same time as generating $\mathrm{H}_{2} \mathrm{O}_{2}$, and a significant difference in $\mathrm{pH}(P<0.001)$ was observed between the control sample and UHT skim milk treated with the highest LO concentration $(0.12 \mathrm{~g} / \mathrm{L})$ at d 4 of storage. By d 14 of storage, these significant differences remained. By d 7 , all treatments were significantly lower $(P<0.05)$ in $\mathrm{pH}$ than the control. By the end of the trial, d 21, the control remained at approximately 6.7 , whereas the lower LO treatment groups $(0.006$ and $0.012 \mathrm{~g} / \mathrm{L})$ were above 6.4 , and the highest concentration of $\mathrm{LO}(0.12$ $\mathrm{g} / \mathrm{L})$ was 6.2. The presence of lactic acid bacteria was likely not the driving cause of this $\mathrm{pH}$ reduction, as UHT skim milk was used, and the $\mathrm{pH}$ of the control increased throughout the trial. Therefore, in the treatment groups, the production of LBA by the LO reaction in solution likely resulted in the $\mathrm{pH}$ reduction.

Lactobionic acid is obtained from the oxidation of lactose, which has metal-chelating and humectant properties. It has many potential applications in foods and pharmaceutical products (Gutiérrez et al., 2012). Lactobionic acid has shown inhibition of L. monocytogenes when combined with other antimicrobial compounds at $21^{\circ} \mathrm{C}$ in $2 \%$ milk, but has not resulted in inhibition when added to milk alone (Chen and Zhong, 2017). Therefore, the combination of LBA with other antimicrobials such as $\mathrm{H}_{2} \mathrm{O}_{2}$ may show further inhibition in milk. Results from the same study showed that the addition of LBA to $2 \%$ milk significantly reduced the $\mathrm{pH}$ of the milk after addition by 0.44 units at a concentration of $10 \mathrm{mg} / \mathrm{L}$ (Chen and Zhong, 2017), consistent with the results obtained from this study. The exact mechanism of action of LBA is currently not well known; however, it is thought that it is due to its chelating and oxidation properties. Furthermore, in our study, measuring a reduction in $\mathrm{pH}$ was an indirect measurement of LBA concentration in the milk. It is not well known exactly how much LBA is produced by this reaction; therefore, future studies should determine the titratable acidity of the milk to quantify this value.

\section{High Concentration With LO Inhibits L. Monocytogenes Outgrowth in UHT Skim Milk Over $48 \mathrm{~h}$}

In the previously established LO treatment levels, L. monocytogenes counts did not increase between the start of the trial and d 2 (Figures 1 and 2). We were interested if higher concentrations of $\mathrm{LO}$ would reduce L. monocytogenes levels during those $48 \mathrm{~h}$ compared with the control. We challenged the LO with a moder- ate, $3 \log \mathrm{cfu} / \mathrm{mL}$, and high, $5 \log \mathrm{cfu} / \mathrm{mL}$, inoculum of $L$. monocytogenes. At the moderate inoculum, the control grew approximately $1 \mathrm{log} \mathrm{cfu} / \mathrm{mL}$ in $48 \mathrm{~h}$, as shown in Figure 3. The lowest concentration of LO, $0.12 \mathrm{~g} / \mathrm{L}$, was significantly different from the control $(P$ $<0.0001$ ) at h 8 of storage. At h 48 , this concentration was $1.2 \log \mathrm{cfu} / \mathrm{mL}$ below the control. At h 24 of storage, the control reached $3.5 \log \mathrm{cfu} / \mathrm{mL}$, and the $1.2 \mathrm{~g} / \mathrm{L}$ LO treatment group was reduced to $2.7 \log \mathrm{cfu} / \mathrm{mL}$. This inhibition continued to $\mathrm{h} 48$ of storage when the control grew out to $4.0 \log \mathrm{cfu} / \mathrm{mL}$ and the treatment was further reduced to $2.3 \log \mathrm{cfu} / \mathrm{mL}$. The highest concentration, $12 \mathrm{~g} / \mathrm{L}$, showed significant differences from the control group throughout the entire period of storage. At h 12, this treatment fell to $2.4 \log \mathrm{cfu} / \mathrm{mL}$, whereas the control reached a level of $3.5 \log \mathrm{cfu} / \mathrm{mL}$. On h 48 of storage, the control reached levels of $4 \mathrm{log}$ $\mathrm{cfu} / \mathrm{mL}$ and the treatment group was further reduced to $1.6 \log \mathrm{cfu} / \mathrm{mL}$. Each of these treatments showed a bacteriostatic effect throughout the entire trial.

In the high inoculum challenge with $5 \log \mathrm{cfu} / \mathrm{mL}$, all treatment groups were significantly lower than the $(P<0.05)$ from the control from $\mathrm{h} 2$ and remained significantly lower throughout the trial (Figure 4). By hour 48 of storage, the $0.12 \mathrm{~g} / \mathrm{L}$ concentration of LO was $1.1 \log \mathrm{cfu} / \mathrm{mL}$ less than the control. The second highest LO treatment, $1.2 \mathrm{~g} / \mathrm{L}$, was not statistically significant from the $0.12 \mathrm{~g} / \mathrm{L}$ treatment throughout the entire trial. By h 48 of storage, this treatment demonstrated a $1.2 \log \mathrm{cfu} / \mathrm{mL}$ reduction from the control. The highest concentration of LO, $12 \mathrm{~g} / \mathrm{L}$, showed the most efficacy toward reduction of $L$. monocytogenes in UHT skim milk when inoculated at $5 \log \mathrm{cfu} / \mathrm{mL}$. By h 24, this treatment was significantly different from both the control $(P<0.05)$ and the 0.12 and $1.2 \mathrm{~g} / \mathrm{L}$ treatments $(P<0.05)$. At $\mathrm{h} 36$, this treatment was approximately $0.8 \log \mathrm{cfu} / \mathrm{mL}$ below the control. By h 48 , the control grew out to almost $6 \log \mathrm{cfu} / \mathrm{mL}$, whereas the $12 \mathrm{~g} / \mathrm{L}$ treatment was reduced to $4 \log \mathrm{cfu} / \mathrm{mL}$.

However, the higher levels of LO showed significant differences in the $\mathrm{pH}$ from the control over the 48-h trial (Table 3). By h 12, the $\mathrm{pH}$ of the highest concentration of LO, $12 \mathrm{~g} / \mathrm{L}$, dropped to 6.55 and was significantly different $(P<0.05)$ from the $\mathrm{pH}$ of the control. Significant differences in $\mathrm{pH}$ were not observed between the control and the lowest LO level of $0.12 \mathrm{~g} / \mathrm{L}$ throughout the trial. By h 48 of storage, the $1.2 \mathrm{~g} / \mathrm{L}$ LO concentration was significantly different $(P<0.05)$ from the control. The $12 \mathrm{~g} / \mathrm{L}$ LO concentration reached a $\mathrm{pH}$ of 6.44 by the end of the 48-h storage period, a 0.23-unit drop below the control.

The higher concentrations of LO used in the 48-h trials showed greater inhibition of L. monocytogenes. As noted earlier, these observations were likely due to 


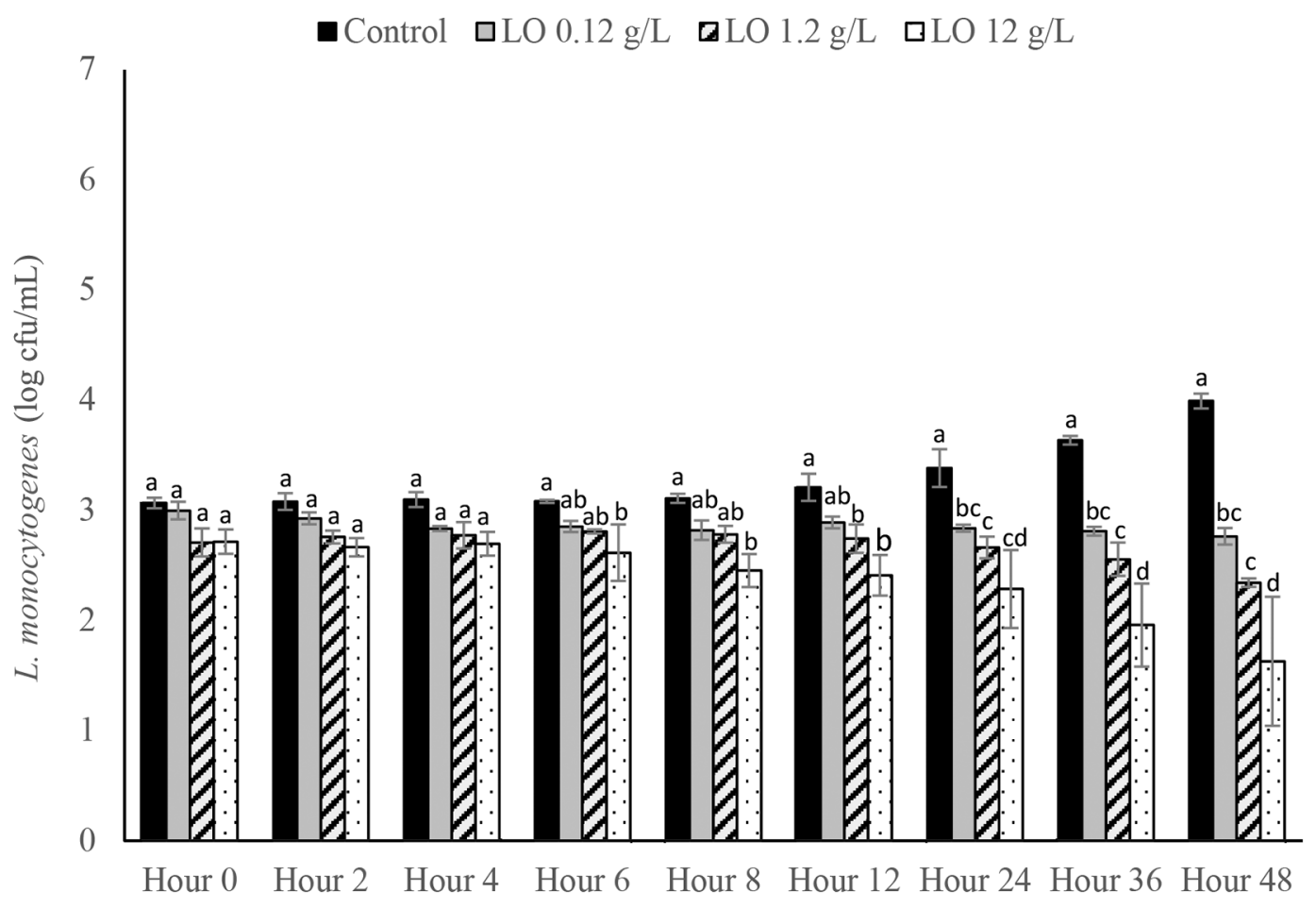

Figure 3. Listeria monocytogenes counts inoculated at $3 \mathrm{log} \mathrm{cfu} / \mathrm{mL}$ in UHT skim milk treated with lactose oxidase (LO) during storage at $6^{\circ} \mathrm{C}$. Numbers on the treatment label indicate the concentration of LO solution $(\mathrm{g} / \mathrm{L})$. Bars with different letters (a-d) indicate significant differences $(P<0.05)$ between treatments on the same day. Error bars represent the SD.

greater production of $\mathrm{H}_{2} \mathrm{O}_{2}$ that $\mathrm{LO}$ produces. Kozak et al. (2018) found that a concentration of $100 \mathrm{mg} / \mathrm{L}$ of $\mathrm{H}_{2} \mathrm{O}_{2}$ inhibited L. monocytogenes growth in UHT whole milk over a period of $21 \mathrm{~d}$, whereas concentrations of $400 \mathrm{mg} / \mathrm{L}$ and $800 \mathrm{mg} / \mathrm{L}$ were bactericidal within $24 \mathrm{~h}$ of storage. Furthermore, Martin et al. (2014) concluded that the higher concentration of $\mathrm{H}_{2} \mathrm{O}_{2}$ in raw milk reduced total bacterial concentrations in raw milk when stored at $6^{\circ} \mathrm{C}$. Our results that showed that higher concentrations of LO produced a greater antimicrobial effect were consistent with these studies. However, the large drop in $\mathrm{pH}$, particularly at the highest LO concentration used, means that there is a potential effect on the milk in a way that may not be sensorially acceptable. Furthermore, LO may produce oxidative flavors that consumers may not find acceptable, which should be investigated in future studies. Future research is needed to investigate whether other methods for LO use, such as immobilization, might allow for the use of higher levels of the enzyme to produce high level of $\mathrm{H}_{2} \mathrm{O}_{2}$ to achieve the bactericidal effects observed in the Kozak et al. (2018) study, and to also minimize the effect on $\mathrm{pH}$ by controlling exposure time of the milk to LO. If milk is to be made into cheese using starter cultures, topical application of the treatment to prevent environmental contamination of L. monocytogenes may be a way to minimize the antimicrobial effect of $\mathrm{LO}$ on catalase-negative starter cultures.

\section{Effect of LO on Raw Milk pH}

The LO treatments significantly reduced the $\mathrm{pH}$ of the raw milk comparison to the control by d 2 of storage (Table 4). By d 7 of storage, the $0.6 \mathrm{~g} / \mathrm{L} \mathrm{LO}$ and $0.6 \mathrm{~g} / \mathrm{L}$ LO-TCN treatments had a $\mathrm{pH}$ approximately 0.3 units lower than the control. Furthermore, the 1.2 $\mathrm{g} / \mathrm{L} \mathrm{LO}$ and $1.2 \mathrm{~g} / \mathrm{L}$ LO-TCN treatments were more than $0.3 \mathrm{pH}$ units below the control on $\mathrm{d} 7$ of storage. Supplementation with TCN appeared to have no effect on the $\mathrm{pH}$ in comparison to the $\mathrm{LO}$ treatment. As noted earlier, the observed $\mathrm{pH}$ drop was due to LBA produced by LO. The implications of the $\mathrm{pH}$ drop on sensory acceptance of the raw milk or of cheese made from LO-treated raw milk need further investigation.

\section{Application of LO and TCN Provide a Bacteriostatic Effect on L. monocytogenes in Raw Milk}

Supplementation with TCN assists activation of the LPDS, a natural antimicrobial system present in raw milk. The LPDS is comprised of the following 3 components: lactoperoxidase, TCN, and $\mathrm{H}_{2} \mathrm{O}_{2}$ (Kussendrager 
Flynn et al.: INHIBITION OF LISTERIA MONOCYTOGENES IN MILK

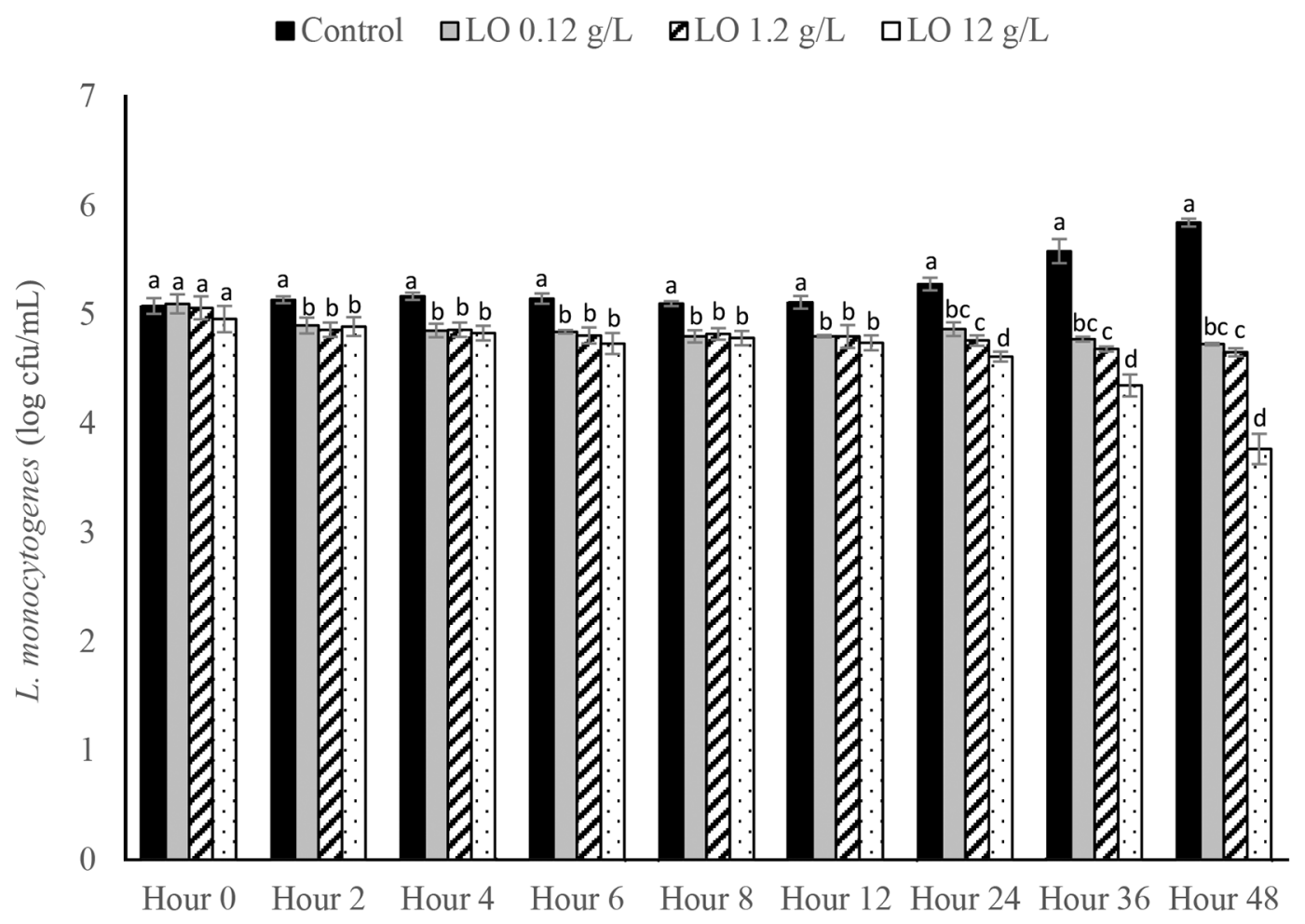

Figure 4. Listeria monocytogenes counts inoculated at $5 \mathrm{log} \mathrm{cfu} / \mathrm{mL}$ in UHT skim milk treated with lactose oxidase (LO) during storage at $6^{\circ} \mathrm{C}$. Numbers on the treatment label indicate the concentration of $\mathrm{LO}$ solution $(\mathrm{g} / \mathrm{L})$. Bars with different letters (a-d) indicate significant differences $(P<0.05)$ between treatments on the same day. Error bars represent the SD.

and van Hooijdonk, 2000). Ultra-high temperature pasteurization completely inactivates the lactoperoxidase enzyme (Barrett et al., 1999), leading to no possible activation of the LPDS in UHT skim milk. Also, Lara-Aguilar and Alcaine (2019a) determined that supplementation of raw milk with TCN alone had no antimicrobial efficacy on Pseudomonas fragi counts, which reinforced the theory of TCN supplementation having a synergistic effect with LO. For these reasons, we did not test TCN supplementation in UHT skim milk or TCN supplementation alone in raw milk and its efficacy against L. monocytogenes. Furthermore, in real-world situations, L. monocytogenes contamination is more of a concern in milk that will not see a pasteurization step, and thus it is important to understand how LO works in such products.

Similar to the UHT skim milk experiments, LO-treated raw milk was challenged with 2 inoculation scenarios with a low and high load of $2 \log \mathrm{cfu} / \mathrm{mL}$ and $4 \log \mathrm{cfu} /$ $\mathrm{mL}$, respectively. In both scenarios, L. monocytogenes exhibited a slower outgrowth in raw milk than in UHT skim milk (Figures 5 and 6 ), with low inoculum reaching $5.3 \mathrm{log} \mathrm{cfu} / \mathrm{mL}$ (Figure 1) in UHT skim milk in $7 \mathrm{~d}$, whereas it only reached $3.1 \log \mathrm{cfu} / \mathrm{mL}$ in the raw milk (Figure 5). Similarly, outgrowth of the positive control with the high inoculum reached $>7 \log \mathrm{cfu} / \mathrm{mL}$ after 7 d (Figure 2) in the UHT milk, whereas it only reached a level of $5.8 \log \mathrm{cfu} / \mathrm{mL}$ (Figure 6 ) in the raw milk.

Multiple reasons can explain the discrepancy between the growth of $L$. monocytogenes in raw milk versus UHT skim milk, with the background microbiota being the primary cause. Raw milk contains a variety of microorganisms, including a large lactic acid bacteria population. In descending order, this lactic acid bacteria population typically includes Lactococcus, Streptococcus, Lactobacillus, Leuconostoc, and Enterococcus spp. (Quigley et al., 2013). Psychrotrophic bacteria, including Pseudomonas, Acinetobacter, and Aeromonas spp. are present in raw milk and thrive at cold temperatures (Raats et al., 2011). The background microbiota present in raw milk may make it difficult for L. monocytogenes to proliferate. A study by Jia et al. (2020) concluded that L. monocytogenes growth was affected by background microbiota in commerciallyproduced salmon when compared with a sterile salmon sample. Furthermore, Gonzales-Barron et al. (2020) found that L. monocytogenes could grow slightly in pasteurized milk and raw milk cheeses; however, the pasteurized milk cheese showed greater outgrowth of L. monocytogenes than raw milk cheese, likely due to a 


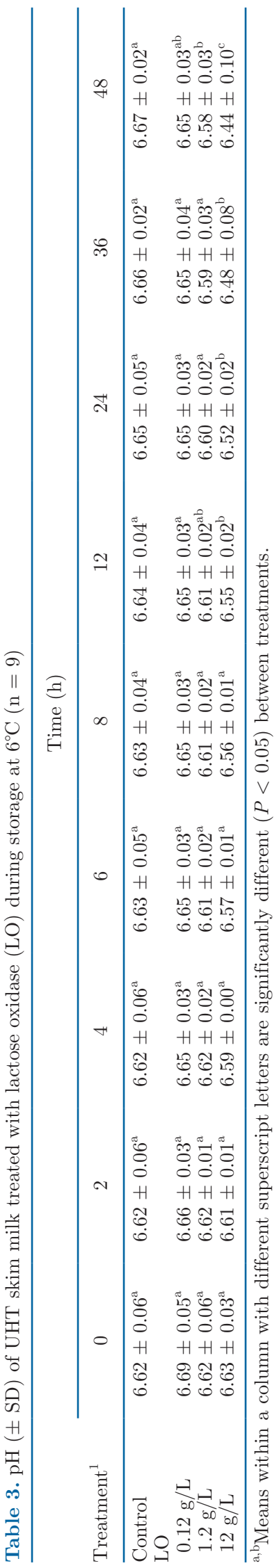

less complex background microbiota. Our results were consistent with those of other studies that show that L. monocytogenes better proliferates in environments with fewer other microorganisms present and grows to higher levels in environments with fewer microorganisms present.

Figure 7 shows the SPC of the microbial population present in raw milk control samples with no L. monocytogenes inoculation over a 7 -d storage period. The high and low L. monocytogenes inocula are included in the graphs for reference. These figures show that the initial concentration of microorganisms present in the raw milk was approximately $3.4 \pm 0.5 \log \mathrm{cfu} / \mathrm{mL}$ on d 0 of storage. Within $2 \mathrm{~d}$ of storage at refrigeration temperatures, this concentration increased to $6.0 \pm 1.5$ $\log \mathrm{cfu} / \mathrm{mL}$. After $7 \mathrm{~d}$ of storage, these counts reached $8.3 \pm 0.16 \log \mathrm{cfu} / \mathrm{mL}$, indicating that a complex background microbiota was present in the raw milk at this time point. The growth of microorganisms in the raw milk by d 2 of storage can help explain why L. monocytogenes exhibited a slow outgrowth within the raw milk samples. On d 2 of storage with both the $2 \log \mathrm{cfu} / \mathrm{mL}$ and $4 \log \mathrm{cfu} / \mathrm{mL}$ inoculation trials, L. monocytogenes exhibited only slight outgrowth, suggesting it competes poorly in the presence of other microorganisms.

At low concentrations, LO efficacy was reduced in raw milk, but the supplementation with TCN restored some efficacy. For example, the effect of an LO treatment of $0.12 \mathrm{~g} / \mathrm{L}$ in raw milk on both low and high inocula of $L$. monocytogenes did not inhibit outgrowth in comparison to the control (Figures 5 and 6), though that concentration was able to inhibit growth in UHT milk (Figures 1 and 2). This reduction of efficacy may be due to the fact that in raw milk, there are other factors that affect $\mathrm{H}_{2} \mathrm{O}_{2}$ such as the presence of background microbiota that in essence divert the activity of $\mathrm{H}_{2} \mathrm{O}_{2}$ away from $L$. monocytogenes. There may also be species in the raw milk that produce a sufficient level of catalase to degrade the $\mathrm{H}_{2} \mathrm{O}_{2}$ produced by this low level of LO, as well as the lactoperoxidase present in the milk. However, with the supplementation of TCN at $14 \mathrm{mg} / \mathrm{mL}$, the $0.12 \mathrm{~g} / \mathrm{L} \mathrm{LO}$ was sufficient to inhibit L. monocytogenes outgrowth (Figures 5 and 6).

This was also observed with Pseudomonas fragi inhibition in raw milk (Lara-Aguilar and Alcaine, 2019a). $\mathrm{H}_{2} \mathrm{O}_{2}$ activates the LPDS, which uses $\mathrm{H}_{2} \mathrm{O}_{2}$ to oxidize TCN, and in turn leads to the formation of antimicrobial compounds (Seifu et al., 2005). It is possible that the level of TCN in raw milk is insufficient to produce enough antimicrobial compounds to inhibit $L$. monocytogenes, and the excess $\mathrm{H}_{2} \mathrm{O}_{2}$ produced by LO is lost. With supplementation of TCN, there is more substrate for lactoperoxidase to produce antimicrobial compounds and thus inhibit L. monocytogenes. This 
Table 4. $\mathrm{pH}( \pm \mathrm{SD})$ of raw milk treated with thiocyanate (TCN) and lactose oxidase (LO) during storage at $6^{\circ} \mathrm{C}(\mathrm{n}=4)$

\begin{tabular}{lcccc}
\hline & \multicolumn{4}{c}{ Time $(\mathrm{d})$} \\
\cline { 2 - 5 } Treatment $^{1}$ & 0 & 2 & 4 & 7 \\
\hline Control & $6.78 \pm 0.01^{\mathrm{a}}$ & $6.78 \pm 0.01^{\mathrm{a}}$ & $6.78 \pm 0.03^{\mathrm{a}}$ & $6.68 \pm 0.05^{\mathrm{a}}$ \\
$\mathrm{LO}$ & & & \\
$0.12 \mathrm{~g} / \mathrm{L}$ & $6.77 \pm 0.02^{\mathrm{a}}$ & $6.74 \pm 0.01^{\mathrm{a}}$ & $6.69 \pm 0.00^{\mathrm{a}}$ & $6.63 \pm 0.06^{\mathrm{a}}$ \\
$0.6 \mathrm{~g} / \mathrm{L}$ & $6.75 \pm 0.02^{\mathrm{a}}$ & $6.67 \pm 0.03^{\mathrm{ab}}$ & $6.60 \pm 0.09^{\mathrm{b}}$ & $6.40 \pm 0.12^{\mathrm{b}}$ \\
$1.2 \mathrm{~g} / \mathrm{L}$ & $6.73 \pm 0.03^{\mathrm{a}}$ & $6.62 \pm 0.05^{\mathrm{b}}$ & $6.51 \pm 0.07^{\mathrm{b}}$ & $6.36 \pm 0.15^{\mathrm{b}}$ \\
TCN with LO & & & \\
$0.12 \mathrm{~g} / \mathrm{L}$ & $6.77 \pm 0.03^{\mathrm{a}}$ & $6.73 \pm 0.01^{\mathrm{a}}$ & $6.69 \pm 0.00^{\mathrm{a}}$ & $6.62 \pm 0.05^{\mathrm{a}}$ \\
$0.6 \mathrm{~g} / \mathrm{L}$ & $6.72 \pm 0.02^{\mathrm{a}}$ & $6.67 \pm 0.04^{\mathrm{b}}$ & $6.55 \pm 0.04^{\mathrm{b}}$ & $6.41 \pm 0.15^{\mathrm{b}}$ \\
$1.2 \mathrm{~g} / \mathrm{L}$ & $6.73 \pm 0.02^{\mathrm{a}}$ & $6.61 \pm 0.07^{\mathrm{b}}$ & $6.52 \pm 0.08^{\mathrm{b}}$ & $6.27 \pm 0.19^{\mathrm{b}}$ \\
\hline
\end{tabular}

${ }^{\mathrm{a}, \mathrm{b}}$ Means within a column with different superscript letters are significantly different $(P<0.05)$ between treatments.

also suggests the mechanism of $L$. monocytogenes inhibition by LO in UHT milk versus LO in raw milk is different, and further research is needed to understand these differences.

Treatments with higher levels of LO were effective at inhibiting L. monocytogenes with and without TCN (Figures 5 and 6). When the $2 \mathrm{log} \mathrm{cfu} / \mathrm{mL}$ inoculum was used, concentrations of $0.6 \mathrm{~g} / \mathrm{L} \mathrm{LO}$ alone and combined with TCN and $1.2 \mathrm{~g} / \mathrm{L}$ alone and combined with
TCN differed from the control as well as the $0.12 \mathrm{~g} / \mathrm{L}$ LO treatment by d 4 of the trial. By d 7 of treatment, the $0.6 \mathrm{~g} / \mathrm{L} \mathrm{LO}$ combined with TCN and the $1.2 \mathrm{~g} / \mathrm{L}$ $\mathrm{LO}$ and $1.2 \mathrm{~g} / \mathrm{L}$ combined with TCN reduced the level of $L$. monocytogenes to below the LOD. Similarly, when L. monocytogenes was inoculated into the raw milk at a concentration of $4 \log \mathrm{cfu} / \mathrm{mL}$, each of these treatments were significantly different from the control by d 4 of storage. The $0.6 \mathrm{LO}-\mathrm{TCN}, 1.2 \mathrm{~g} / \mathrm{L} \mathrm{LO}$, and $1.2 \mathrm{~g} / \mathrm{L}$

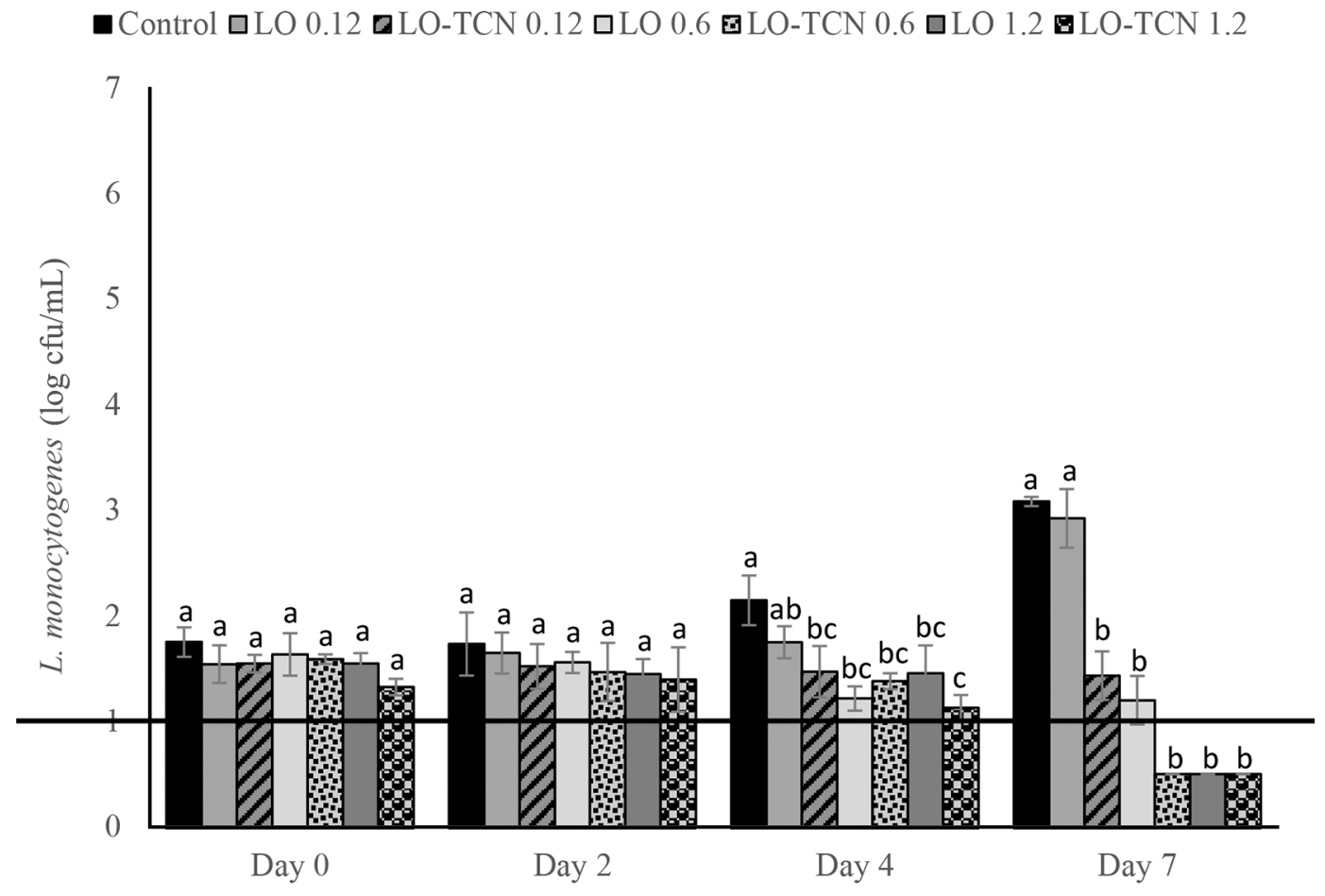

Figure 5. Listeria monocytogenes counts inoculated at $2 \log \mathrm{cfu} / \mathrm{mL}$ in raw milk treated with lactose oxidase (LO) and thiocyanate (TCN) during storage at $6^{\circ} \mathrm{C}$. Numbers on the treatment label indicate the concentration of LO solution $(\mathrm{g} / \mathrm{L})$. Bars with different letters $(\mathrm{a}-\mathrm{c})$ indicate significant differences $(P<0.05)$ between treatments on the same day. For counts lower than the limit of detection, a value of $0.5 \log _{10}$ cfu/mL was used. A horizontal line was drawn at the limit of detection to represent y $=1.0 \log \mathrm{cfu} / \mathrm{mL}$. The LO treatments were undetectable in $21 \mathrm{~d}$. Error bars represent the SD. 


\section{Control aLO 0.12 a LO-TCN 0.12 aLO 0.6 घLO 0.6-TCN aLO 1.2 घLO 1.2-TCN}

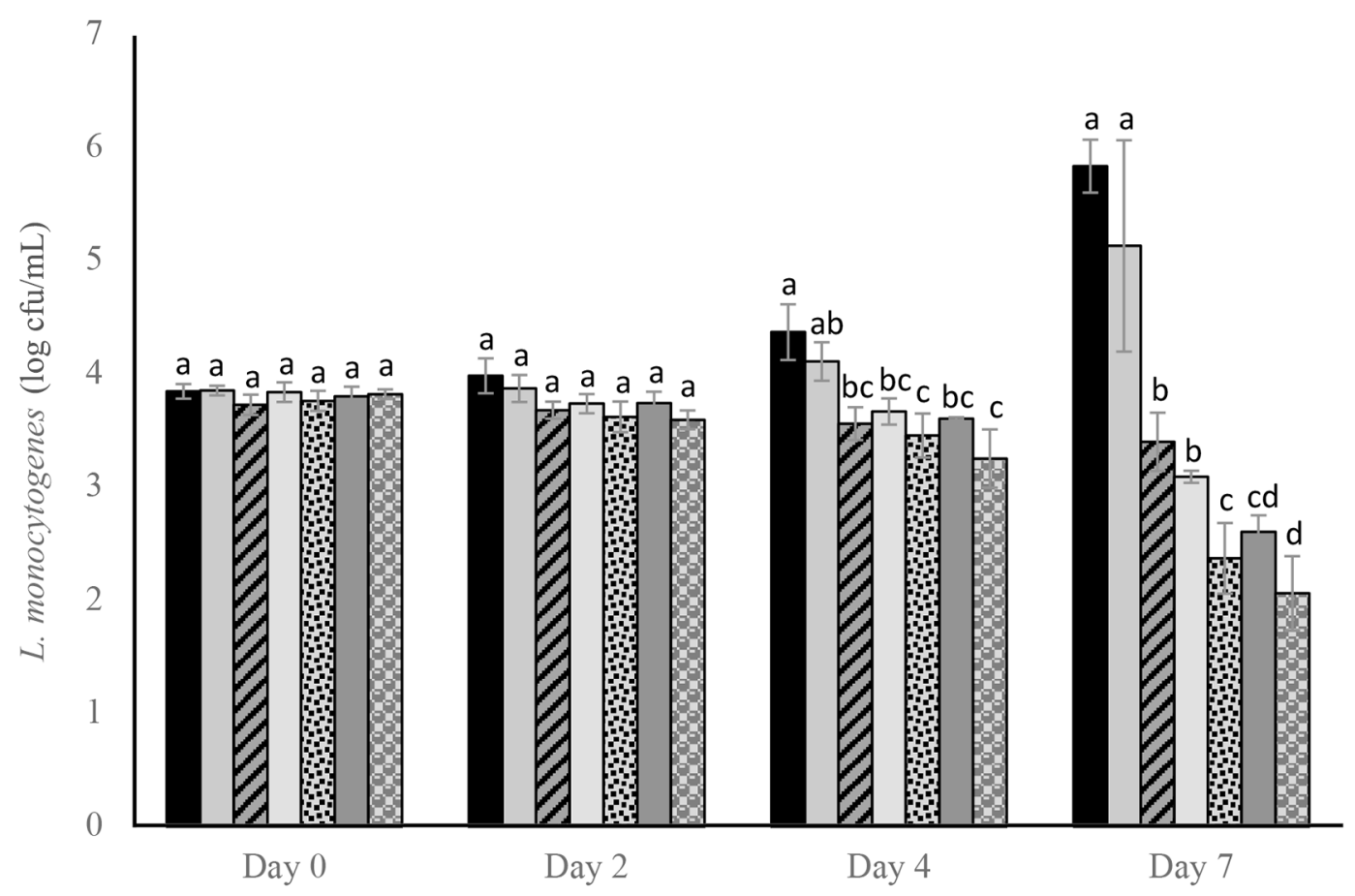

Figure 6. Listeria monocytogenes counts inoculated at $4 \mathrm{log} \mathrm{cfu} / \mathrm{mL}$ in raw milk treated with lactose oxidase (LO) and thiocyanate (TCN) during storage at $6^{\circ} \mathrm{C}$. Numbers on the treatment label indicate the concentration of LO solution $(\mathrm{g} / \mathrm{L})$. Bars with different letters $(\mathrm{a}-\mathrm{d})$ indicate significant differences $(P<0.05)$ between treatments on the same day. Error bars represent the SD.

LO-TCN treatments all reduced levels of L. monocytogenes to below $3 \log \mathrm{cfu} / \mathrm{mL}$; a bacteriostatic effect was present using these levels. Higher concentrations of LO had more of an effect against L. monocytogenes in raw milk.

\section{CONCLUSIONS}

The goal of this study was to explore the possible antimicrobial effect of $\mathrm{LO}$ on L. monocytogenes in various milk products as a possible safety enhancement to prevent the pathogen's outgrowth. We first explored the antimicrobial effects of LO to reduce $L$. monocytogenes counts in UHT skim milk and then used these results for investigation of further application in other milk products. Our results showed that very low concentrations $(0.006,0.012$, and $0.12 \mathrm{~g} / \mathrm{L} \mathrm{LO})$ were effective at inhibiting L. monocytogenes inoculated at both 2 $\log \mathrm{cfu} / \mathrm{mL}$ and $4 \log \mathrm{cfu} / \mathrm{mL}$ concentrations in UHT skim milk. Each of these treatments had minimal effect on the $\mathrm{pH}$ until d 4 of storage; by d 7 of storage all treatments differed significantly in $\mathrm{pH}$ from the control due to the production of LBA. We observed that the highest concentration of $\mathrm{LO}$ that proved effective in the
UHT trials did not have the same effect on L. monocytogenes in raw milk, likely due to the presence of a diverse microbiota as well as the presence of the LPDS in raw milk. Therefore, we increased concentrations of LO and supplemented with sodium TCN. These concentrations proved inhibitory to outgrowth of L. monocytogenes during a 1-wk storage period, demonstrating that LO and LO supplemented with TCN are effective and could be leveraged to improve the food safety of dairy products. Future studies will evaluate the efficacy of LO as an inhibitor of L. monocytogenes and other pathogenic organisms in other dairy products, such as cheese and yogurt.

\section{ACKNOWLEDGMENTS}

The authors thank the New York State Milk Promotion Advisory Board (Albany, NY) for their support of this project through the New York State Department of Agriculture and Markets (Albany, NY). The authors also thank the staff and students of the Cornell Food Safety Laboratory (Cornell University, Ithaca, NY) for allowing us to use their space. The authors have not stated any conflicts of interest. 

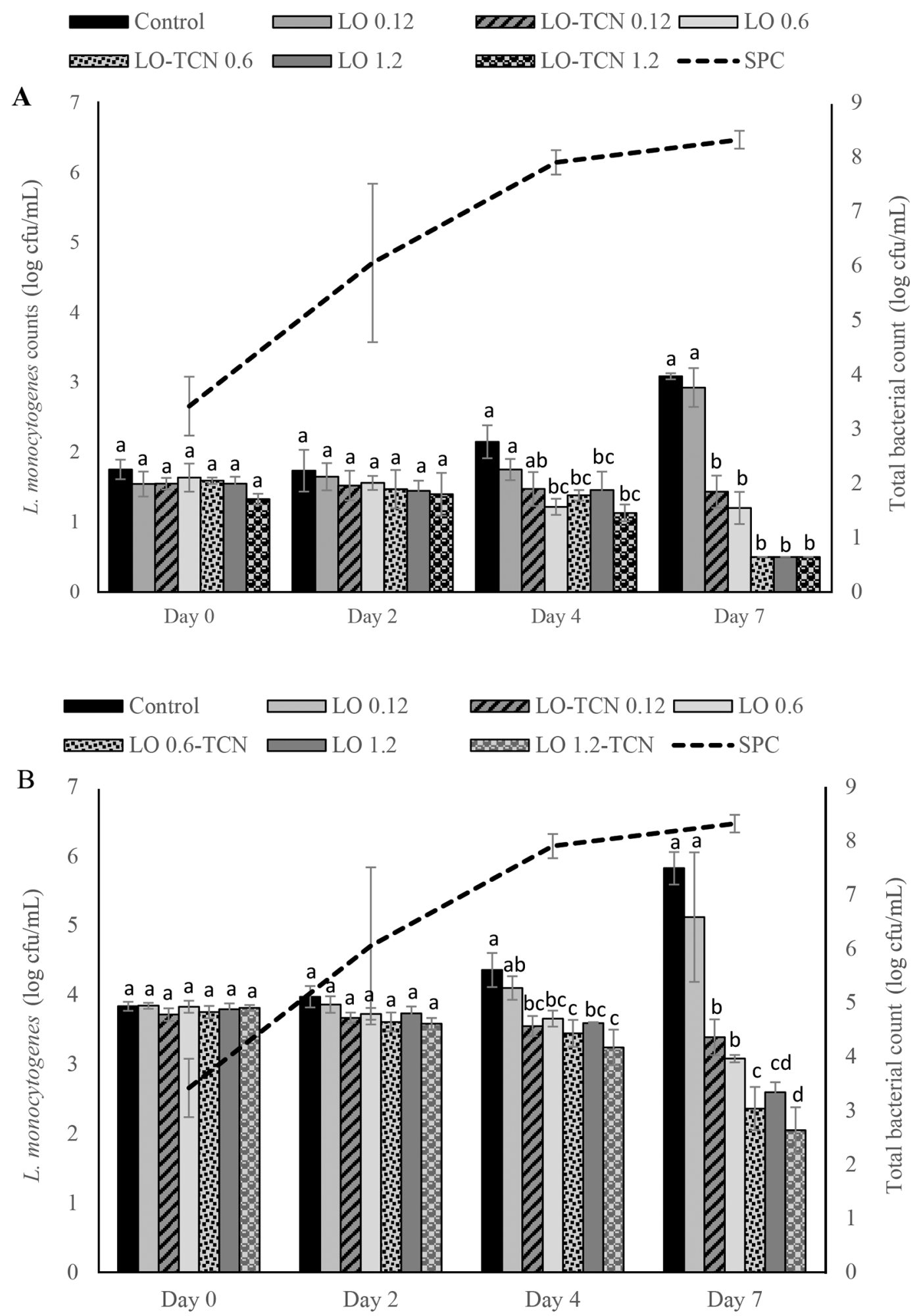

Figure 7. (A) Total bacterial growth curve in raw milk. The $2 \log$ cfu/mL inoculum of Listeria monocytogenes in raw milk was plotted for comparison. Error bars represent the SD. (B) Total bacterial growth curve in raw milk. The $4 \log$ cfu/mL inoculum of L. monocytogenes was plotted for comparison. Error bars represent the SD. 


\section{REFERENCES}

Ahmad, S. K., D. S. Brinch, E. P. Friis, and P. B. Pedersen. 2004 Toxicological studies on lactose oxidase from Microdochium nivale expressed in Fusarium venenatum. Regul. Toxicol. Pharmacol. 39:256-270. https://doi.org/10.1016/j.yrtph.2004.02.003.

Asioli, D., J. Aschemann-Witzel, V. Caputo, R. Vecchio, A. Annunziata, T. Naes, and P. Varela. 2017. Pages 58-71 in Making sense of the "clean label" trends: A review of consumer food choice behavior and discussion of industry implications. Food Research International.

Barrett, N. E., A. S. Grandison, and M. J. Lewis. 1999. Contribution of the lactoperoxidase system to the keeping quality of pasteurized milk. J. Dairy Res. 66:73-80. https://doi.org/10.1017/ S0022029998003252.

Barría, C., R. S. Singer, I. Bueno, E. Estrada, D. Rivera, S. Ulloa, J. Fernández, F. O. Mardones, and A. I. Moreno-Switt. 2020. Tracing Listeria monocytogenes contamination in artisanal cheese to the processing environments in cheese producers in southern Chile. Food Microbiol. 90:103499. https://doi.org/10.1016/j.fm.2020 .103499 .

Ben Amira, A. B., S. Besbes, H. Attia, and C. Blecker. 2017. Milkclotting properties of plant rennets and their enzymatic, rheological, and sensory role in cheese making: A review. Int. J. Food Prop. 20(sup1):S76-S93. https://doi.org/10.1080/10942912.2017 .1289959 .

Berger, S. 2017. Listeriosis global status. Gideon.

Boor, K. J., M. Wiedmann, S. Murphy, and S. Alcaine. 2017. A 100Year Review: Microbiology and safety of milk handling. J. Dairy Sci. 100:9933-9951. https://doi.org/10.3168/jds.2017-12969.

Centers for Disease Control and Prevention. 2020. Listeria outbreaks. Accessed Jul. 21, 2021. https://www.cdc.gov/listeria/outbreaks/ index.html.

Chen, H., and Q. Zhong. 2017. Lactobionic acid enhances the synergistic effect of nisin and thymol against Listeria monocytogenes Scott A in tryptic soy broth and milk. Int. J. Food Microbiol. 260:36-41. https://doi.org/10.1016/j.ijfoodmicro.2017.08.013.

Coelho, M. C., C. C. G. Silva, S. C. Ribeiro, M. L. N. E. Dapkevicius, and H. J. D. Rosa. 2014. Control of Listeria monocytogenes in fresh cheese using protective lactic acid bacteria. Int. J. Food Microbiol. 191:53-59. https://doi.org/10.1016/j.ijfoodmicro.2014.08.029.

Curtis, G., W. Nichols, and T. Falla. 1989. Selective agents for Listeria can inhibit their growth. Lett. Appl. Microbiol. 8:169-172. https:/ /doi.org/10.1111/j.1472-765X.1989.tb00240.x.

D'Amico, D. J., M. J. Druart, and C. W. Donnelly. 2008. 60-day aging requirement does not ensure safety of surface-mold-ripened soft cheeses manufactured from raw or pasteurized milk when Listeria monocytogenes is introduced as a postprocessing contaminant. J. Food Prot. 71:1563-1571. https://doi.org/10.4315/0362-028X-71.8 .1563 .

de Noordhout, C. M., B. Devleesschauwer, F. J. Angulo, G. Verbeke, J. Haagsma, M. Kirk, A. Havelaar, and N. Speybroeck. 2014. The global burden of listeriosis: A systematic review and meta-analysis. Lancet Infect. Dis. 14:1073-1082. https://doi.org/10.1016/S1473 -3099(14)70870-9.

Duke, F. R., M. Weibel, D. S. Page, V. G. Bulgrin, and J. Luthy. 1969. Glucose oxidase mechanism. Enzyme activation by substrate. J. Am. Chem. Soc. 91:3904-3909.

EFSA Panel on Food Contact Materials, Enzymes and Processing Aids (EFSA CEP Panel), V. Silano, J. M. Barat Baviera, C. Bolognesi, B. J. Brüschweiler, P. S. Cocconcelli, R. Crebelli, D. M. Gott, K. Grob, E. Lampi, and A. Mortensen. 2019. Safety evaluation of the food enzyme glucose oxidase from Aspergillus niger (strain ZGL). EFSA J. 17:e05629.

FAO/WHO. 2006. Benefits and Potential Risks of the Lactoperoxidase System of Raw Milk Preservation. FAO; 5-11.

FDA. 2015. Joint FDA/Health Canada Quantitative Assessment of the Risk of Listeriosis from Soft-Ripened Cheese Consumption in the United States and Canada: Report Vol. 2020. Accessed Jan. 10, 2021. https://www.fda.gov/food/cfsan-risk-safety-assessments/ joint-fda-health-canada-quantitative-assessment-risk-listeriosis -soft-ripened-cheese-consumption.

FDA. 2018. Microbiological Surveillance Sampling: FY14:-16 Raw Milk Cheese Aged 60 Days. Accessed Jan. 10, 2021. https:// www.fda.gov/food/sampling-protect-food-supply/microbiological -surveillance-sampling-fy 14-16-raw-milk-cheese-aged-60-days.

FDA. 2019a. CFR- Code of Federal Regulations Title 21.184.1366. Accessed Jan. 10, 2021. https://www.ecfr.gov/cgi-bin/text-idx?SID = 94daefb25e6904244d7b76a745d30718\&mc=true\&node=se21.3.184 $-11366 \&$ rgn $=$ div8.

FDA. 2019b. Listeria (Listeriosis). Accessed Jan. 10 2021. https:// www.fda.gov/food/foodborne-pathogens/listeria-listeriosis.

FDA. 2020a. Code of Federal Regulation Title 21, Part 133.182. FDA. Accessed Aug. 21, 2020. https://www.accessdata.fda.gov/scripts/ cdrh/cfdocs/cfcfr/cfrsearch.cfm?fr-133.182.

FDA. 2020b. Code of Federal Regulation Title 21, Part 184. FDA. Accessed Aug. 21, 2020. https://www.accessdata.fda.gov/scripts/ cdrh/cfdocs/cfcfr/CFRSearch.cfm?CFRPart=184.

Fedio, W. M., and H. Jackson. 1992. On the origin of Listeria monocytogenes in raw bulk-tank milk. Int. Dairy J. 2:197-208. https:// doi.org/10.1016/0958-6946(92)90016-F.

Finnegan, M., E. Linley, S. P. Denyer, G. McDonnell, C. Simons, and J.-Y. Maillard. 2010. Mode of action of hydrogen peroxide and other oxidizing agents: differences between liquid and gas forms. J. Antimicrob. Chemother. 65:2108-2115. https://doi.org/10.1093/ $\mathrm{jac} / \mathrm{dkq} 308$.

Gonzales-Barron, U., F. B. Campagnollo, D. W. Schaffner, A. S. Sant'Ana, and V. A. P. Cadavez. 2020. Behavior of Listeria monocytogenes in the presence or not of intentionally-added lactic acid bacteria during ripening of artisanal Minas semi-hard cheese. Food Microbiol. 91:103545.

Govaert, M., C. Smet, D. Verheyen, J. L. Walsh, and J. F. M. Van Impe. 2019. Combined effect of cold atmospheric plasma and hydrogen peroxide treatment on mature Listeria monocytogenes and Salmonella typhimurium Biofilms. Vol. 10. Frontiers Media SA.

Gutiérrez, L.-F., S. Hamoudi, and K. Belkacemi. 2012. Lactobionic acid: A high value-added lactose derivative for food and pharmaceutical applications. Int. Dairy J. 26:103-111. https://doi.org/10 $.1016 /$ j.idairyj.2012.05.003.

Henderson, L. O., L. Cabrera-Villamizar, J. Skeens, D. Kent, S. Murphy, M. Wiedmann, and V. Guariglia-Oropeza. 2019. Environmental conditions and serotype affect Listeria monocytogenes susceptibility to phage treatment in a laboratory cheese model. J. Dairy Sci. 102:9674-9688. https://doi.org/10.3168/jds.2019-16474.

Himonides, A. T., K. D. A. Taylor, and M. J. Knowles. 1999. The improved whitening of cod and haddock flaps using hydrogen peroxide. J. Sci. Food Agric. 79:845-850. https://doi.org/10.1002/ (SICI) 1097-0010(19990501)79:6<845::AID-JSFA297>3.0.CO;2-W.

Jia, Z., W. Bai, X. Li, T. Fang, and C. Li. 2020. Assessing the growth of Listeria monocytogenes in salmon with or without the competition of background microflora-A one-step kinetic analysis. Food Control 114:107139. https://doi.org/10.1016/j.foodcont.2020 .107139 .

Kozak, S. M., S. R. B. Brown, Y. Bobak, and D. J. D'Amico. 2018. Control of Listeria monocytogenes in whole milk using antimicrobials applied individually and in combination. J. Dairy Sci. 101:1889-1900. https://doi.org/10.3168/jds.2017-13648.

Kussendrager, K. D., and A. C. M. van Hooijdonk. 2000. Lactoperoxidase: Physico-chemical properties, occurrence, mechanism of action and applications. Br. J. Nutr. 84(Suppl 1):S19-25. https:// doi.org/10.1017/S0007114500002208.

Lara-Aguilar, S., and S. D. Alcaine. 2019a. Lactose oxidase: A novel activator of the lactoperoxidase system in milk for improved shelf life. J. Dairy Sci. 102:1933-1942. https://doi.org/10.3168/jds.2018 $-15537$.

Lara-Aguilar, S., and S. D. Alcaine. 2019b. Short communication: Screening inhibition of dairy-relevant pathogens and spoilage microorganisms by lactose oxidase. J. Dairy Sci. 102:7807-7812. https://doi.org/10.3168/jds.2019-16757. 
Lawton, M. R., K. G. Jencarelli, S. M. Kozak, and S. D. Alcaine. 2020. Short communication: Evaluation of commercial meat cultures to inhibit Listeria monocytogenes in a fresh cheese laboratory model. J. Dairy Sci. 103:1269-1275. https://doi.org/10.3168/jds .2019-17203.

Linley, E., S. P. Denyer, G. McDonnell, C. Simons, and J.-V. Maillard. 2012. Use of hydrogen peroxide as a biocide: New consideration of its mechanisms of biocidal action. J. Antimicrob. Chemother. 67:1589-1596.

Martin, N. H., A. Friedlander, A. Mok, D. Kent, M. Wiedmann, and K. J. Boor. 2014. Peroxide test strips detect added hydrogen peroxide in raw milk at levels affecting bacterial load. J. Food Prot. 77:1809-1813. https://doi.org/10.4315/0362-028X.JFP-14-074.

Mead, P. S., L. Slutsker, V. Dietz, L. F. McCaig, J. S. Bresee, C. Shapiro, P. M. Griffin, and R. V. Tauxe. 1999. Food-related illness and death in the United States. Emerg. Infect. Dis. 5:607-625. https:/ /doi.org/10.3201/eid0505.990502.

Nordkvist, M., P. M. Nielsen, and J. Villadsen. 2007. Oxidation of lactose to lactobionic acid by a Microdochium nivale carbohydrate oxidase: Kinetics and operational stability. Biotechnol. Bioeng. 97:694-707.

Quigley, L., O. O'Sullivan, C. Stanton, T. P. Beresford, R. P. Ross, G. F. Fitzgerald, and P. D. Cotter. 2013. The complex microbiota of raw milk. FEMS Microbiol. Rev. 37:664-698. https://doi.org/10 $.1111 / 1574-6976.12030$.

Raats, D., M. Offek, D. Minz, and M. Halpern. 2011. Molecular analysis of bacterial communities in raw cow milk and the impact of refrigeration on its structure and dynamics. Food Microbiol. 28:465-471. https://doi.org/10.1016/j.fm.2010.10.009.

Ricchi, M., E. Scaltriti, G. Cammi, C. Garbarino, N. Arrigoni, M. Morganti, and S. Pongolini. 2019. Short communication: Persistent contamination by Listeria monocytogenes of bovine raw milk investigated by whole-genome sequencing. J. Dairy Sci. 102:6032-6036. https://doi.org/10.3168/jds.2019-16267.
Russell, A. D. 2003. Similarities and differences in the responses of microorganisms to biocides. J. Antimicrob. Chemother. 52:750-763. https://doi.org/10.1093/jac/dkg422.

Seifu, E., E. M. Buys, and E. F. Donkin. 2005. Significance of the lactoperoxidase system in the dairy industry and its potential applications: A review. Trends Food Sci. Technol. 16:137-154. https: //doi.org/10.1016/j.tifs.2004.11.002.

Tomasula, P. M., J. A. Renye, D. L. Van Hekken, M. H. Tunick, R. Kwoczak, M. Toht, L. N. Leggett, J. B. Luchansky, A. C. S. PortoFett, and J. G. Phillips. 2014. Effect of high-pressure processing on reduction of Listeria monocytogenes in packaged Queso Fresco. J. Dairy Sci. 97:1281-1295. https://doi.org/10.3168/jds.2013-7538.

Trzaskowska, M., Y. Dai, P. Delaquis, and S. Wang. 2018. Pathogen reduction on mung bean reduction of Escherichia coli O157:H7, Salmonella enterica and Listeria monocytogenes on mung bean using combined thermal and chemical treatments with acetic acid and hydrogen peroxide. J. Food Microbiol. 76:62-68.

Van Tassell, M. L., L. A. Ibarra-Sánchez, S. R. Takhar, S. L. AmayaLlano, and M. J. Miller. 2015. Use of a miniature laboratory fresh cheese model for investigating antimicrobial activities. J. Dairy Sci. 98:8515-8524. https://doi.org/10.3168/jds.2015-9967.

Wehr, H. M., and J. F. Frank, eds. 2004. Pages 21-61 in Standard Methods for the Examination of Dairy Products. 17th ed. American Public Health Association.

\section{ORCIDS}

Brenna T. Flynn () https://orcid.org/0000-0002-1153-613X

Sarah M. Kozak 이 https://orcid.org/0000-0003-2538-1463

Marie R. Lawton () https://orcid.org/0000-0003-0454-2328

Samuel D. Alcaine ๑ https://orcid.org/0000-0001-7953-9145 